\title{
Increased rectal cell proliferation following alcohol abuse
}

\author{
U A Simanowski, N Homann, M Knühl, L Arce, R Waldherr, C Conradt, F X Bosch, \\ H K Seitz
}

\begin{abstract}
Background-Epidemiological data indicate an increased risk for rectal cancer following chronic alcohol consumption. As chronic ethanol ingestion leads to rectal hyperregeneration in experimental animals, indicating a state of increased susceptibility to carcinogens, we studied cell proliferation in alcohol abusers.

Methods-Rectal biopsies were taken from 44 heavy drinkers and 26 controls. Cell proliferation, including proliferative compartment size, was measured by immunohistological staining for proliferative cell nuclear antigen (PCNA) and Ki67, and by in situ hybridisation for histone H3. Quantification of cell proliferation using PCNA staining was evaluated in 27 alcohol abusers and 12 controls. In addition, immunohistology was performed for cytokeratins and gene products of $R b 1$, bcl-2, and p53.
\end{abstract}

Results-Heavy drinking resulted in

Laboratory of Alcohol

Research, Liver

Disease and Nutrition, and Department of

Medicine, Salem

Medical Centre,

Heidelberg, Germany

U A Simanowski

N Homann

M Knühl

L Arce

H K Seitz

Department of

Otorhinolaryngology,

University of

Heidelberg,

Heidelberg, Germany

F X Bosch

Department of Pathology, University of Heidelberg,

Heidelberg, Germany

$\mathrm{R}$ Waldherr

Department of

Biostatistics,

University of

Heidelberg,

Heidelberg, Germany

C Conradt

Correspondence to:

Dr H K Seitz, Department of

Medicine, Salem Medical

Centre, Zeppelinstrasse

11-33, D-69121 Heidelberg,

Germany.helmut_karl.seitz@

urz.uni-heidelberg.de

Accepted for publication

12 February 2001 increased cell proliferation of the rectal mucosa, as shown by increased detection of different proliferation markers. However, cell differentiation regarding cytokeratin expression patterns was unchanged as well as regulatory factors involved in carcinogenesis and/or apoptosis.

Conclusion-Chronic alcohol abuse leads to rectal mucosal hyperproliferation in humans, a condition associated with an increased cancer risk.

(Gut 2001;49:418-422)

Keywords: colorectal cancer; alcohol; rectal mucosa

Colorectal cancer is a leading cause of death in industrial countries. ${ }^{12}$ Epidemiological studies have shown that among other factors, chronic alcohol consumption, even in moderate doses, increases the risk of rectal cancer $^{3-6}$ and colorectal polyps. ${ }^{6-9}$ Various experimental studies have been performed to elucidate the mechanism of the cancer stimulating effect of chronic ethanol ingestion. In rats, it has been shown that concomitant administration of ethanol in a liquid diet promotes rectal carcinogenesis induced by 1,2dimethylhydrazine, ${ }^{10}$ azoxymethane, ${ }^{11}$ and azoxymethylmethylnitrosamine (AMMN). ${ }^{12}$ As AMMN induced rectal carcinogenesis was stimulated by ethanol and as AMMN does not need metabolic activation to become carcinogenic, it was believed that local rather than systemic effects of ethanol may contribute to the cocarcinogenic effect of ethanol in the rectum.
Indeed, in a variety of experimental studies it was shown that chronic ethanol consumption increased mucosal cell regeneration in the rectum, possibly due to acetaldehyde mediated toxicity leading primarily to mucosal cell injury followed by enhanced cell renewal. ${ }^{12-15}$ It is well known from studies in experimental animals $^{16}{ }^{17}$ and humans ${ }^{18}{ }^{19}$ that such mucosal cell hyperregeneration, regardless of its underlying cause, predisposes to the development of colorectal cancer. As no data are available on the effect of chronic ethanol consumption on rectal cellular behaviour in humans, we investigated rectal mucosal cell proliferation, cell differentiation, and tumour suppressor gene/ oncogene expression in chronic alcohol abusers and control subjects.

\section{Materials and methods}

PATIENTS

Twenty seven heavy drinkers (23 males, four females) admitted to the Department of Medicine, Salem Medical Centre, Heidelberg, for alcohol detoxification treatment were included in this study. Mean age was 50.7 (11.8) years (range 29-71). Rectal biopsies (15-20 cm above the anal ring) were taken between the first and fourth day after admission during flexible rectoscopy using a standard colonoscope and biopsy forceps (Olympus Co. Europe, Hamburg, Germany). Alcohol consumption prior to hospitalisation was recorded by face to face interview and exceeded 11 units of alcohol or $100 \mathrm{~g}$ of ethanol per day (1 unit corresponds to $9 \mathrm{~g}$ ) in all cases. Mean ethanol consumption was 15.5 units or $140 \mathrm{~g}$ per day. All patients consumed alcohol up to the day of admission to hospital.

In addition, 12 control patients (five males, seven females) were included in the study. None had gastrointestinal disease or was receiving any medication. All were coloscopied for screening reasons to exclude colorectal pathology during the time period of inclusion of the study patients. Mean age was 46.5 (16.6) years (range 25-74). Alcohol consumption was determined by face to face interview and was less than 3.3 units or $30 \mathrm{~g}$ per day. Smoking was recorded in all but one subject.

IMMUNOHISTOLOGY

Following formalin fixation, routine histological sections of all patients and controls were immunostained for proliferating cell nuclear

Abbreviations used in this paper: ALDH, acetaldehyde dehydrogenase; AMMN, azoxymethylmethylnitrosamine; ck, cytokeratin; PC, proliferative compartment; PCNA, proliferative cell nuclear antigen; PI, proliferation index. 


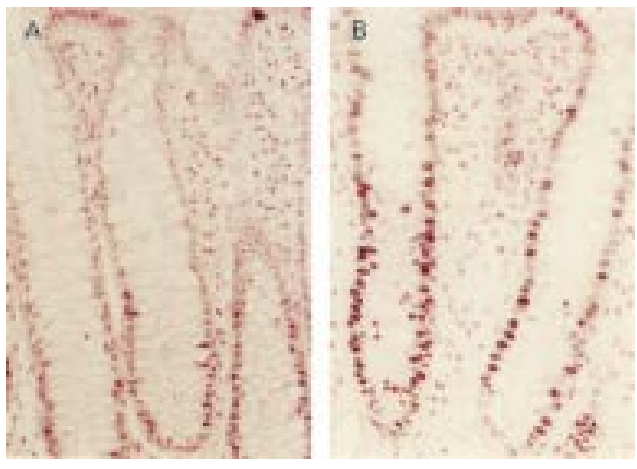

Figure 1 Typical staining patterns of proliferative cell nuclear antigen in nuclei of rectal crypts of controls $(A)$ and alcohol abusers (B) (magnification $\times 100)$.

Table 1 Characteristics of rectal crypts in heavy drinking and control subjects

\begin{tabular}{llll}
\hline & $\begin{array}{l}\text { Alcoholics } \\
(n=27)\end{array}$ & $\begin{array}{l}\text { Controls } \\
(n=12)\end{array}$ & $p$ Value \\
\hline $\begin{array}{l}\text { Crypt height (cells/crypt } \\
\text { collumn) }\end{array}$ & $80.3(8.3)$ & $77.4(8.2)$ & $>0.05$ \\
$\begin{array}{l}\text { PI (\% PCNA positive } \\
\text { cells) }\end{array}$ & $10.8(0.4)$ & $8.6(0.3)$ & $<0.001$ \\
\hline
\end{tabular}

Values are mean (SD).

PI, proliferation index; PCNA, proliferative cell nuclear antigen.

antigen (PCNA) using the PC10 mouse antibody (Dianova, Hamburg, Germany) and the biotin-avidin detection system, according to Weisgerber and colleagues. ${ }^{20}$ In longitudinally sectioned crypts, crypt height (cells per crypt column) as well as the number and location of intensely stained nuclei were recorded. For quantitative analysis the proliferation index (PI) (percentage of stained cells) was calculated for the whole crypt cell column and for five equal crypt compartments, with compartment 1 being at the crypt base and compartment 5 at the crypt-luminar junction, as previously described ${ }^{20}$ Crypt cell columns evaluated were 28.8 (13.3) in heavy drinkers and 30.3 (17.6) in controls. The number of counted cells per individual was 2503 (1095) in the alcohol abusers and 2411 (1484) in controls. Furthermore, extension of the proliferative compartment (PC) was estimated using a graphical method. ${ }^{1321}$

In addition, rectal biopsies of 17 alcohol abusers (10 males, seven females) and 14 age matched controls (six males, eight females) with identical inclusion criteria as above were snap frozen and subjected to an array of different staining procedures: in situ hybridisation for histone $\mathrm{H} 3$ was carried out in three specimens each of patients and controls, as published previously. ${ }^{22}$ The following staining procedures were performed in tissues from all 17 heavy drinkers and 14 controls: Ki67 (MIB-1), regulatory proteins of Rb1, bcl-2 and p53, and cytokeratins (ck). ${ }^{41319}$ All antibodies were commercially available: p53 clone BP53-11 and ck 19 clone Ks 19.2 (Progen, Heidelberg, Germany); Ki67 clone MIB-1 (Dianova, Hamburg, Germany); bcl-2 clone 124 and ck 8 clone 35ßH11 (Dako, Glostrup, Denmark); Rb1 clone 1F8 (Medac, Hamburg, Germany); ck 4 clone M6B10 (EuroDiagostics, Arnhem, Netherlands); and ck 13

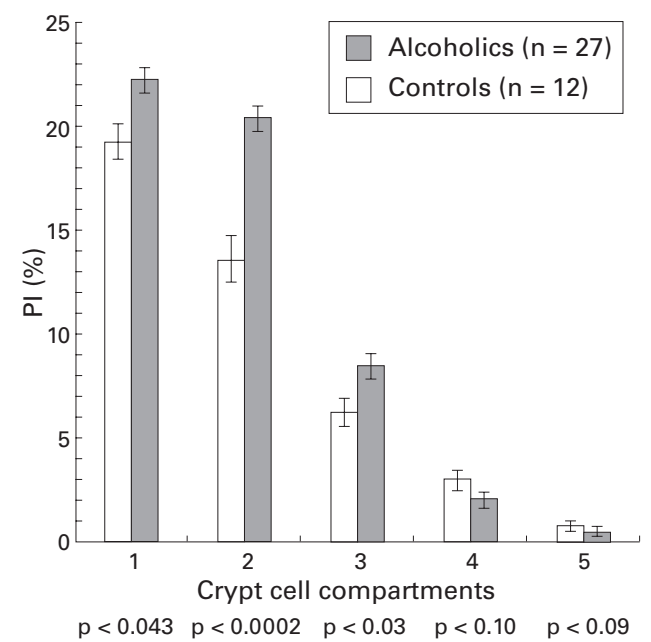

Figure 2 Proliferative indices (PI) in alcohol abusers and controls, expressed as a percentage of proliferative cell nuclear antigen positive cells in a rectal crypt, subdivided into equal crypt cell compartments, with compartment 1 being at the crypt base and compartment 5 adjacent to the crypt-luminar junction.

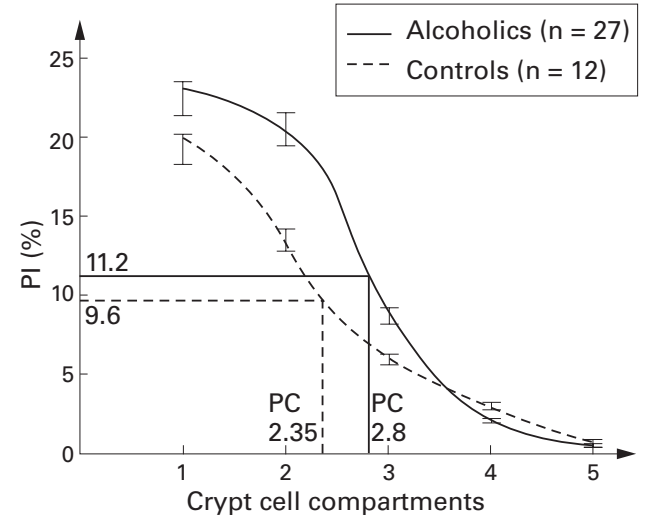

Figure 3 Graphically estimated proliferative compartment (PC) size, expressed as the number of crypt cell

compartments, in alcohol abusers and controls. The limit of $P C$ is $50 \%$ of the peak proliferative index (PI).

clone 1C7 (Laboserv, Giessen, Germany). The detection system used was the alkaline phosphatase-antialkaline phosphatase method, in accordance with the manufacturer's guidelines (Dako, Glostrup, Denmark).

STATISTICAL ANALYSIS

All values are given as mean (SD). PI values were compared using the Students' $t$ test; $p$ values $<0.05$ were considered to be significant. Study and control patients were of similar age. However, due to the imbalance of the possible confounders sex and smoking behaviour, subsequent multivariate analysis was performed: in a multiple regression model with PI being the dependent variable, the adjusted effect of heavy drinking versus none to moderate drinking was tested, with sex and number of cigarettes per day being co-variables.

The study was approved by the ethics committee of the Department of Medicine of the University of Heidelberg.

\section{Results}

Typical staining patterns of PCNA in rectal crypts of study subjects and controls are shown 


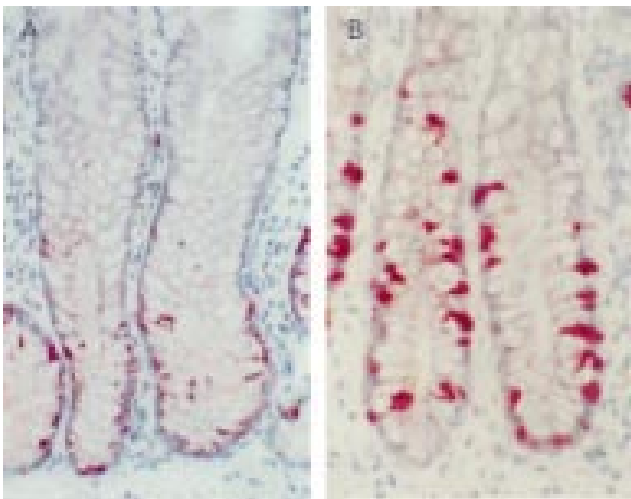

Figure 4 Staining for Ki67 in rectal crypts of controls $(A)$ and alcohol abusers (B) (magnification $\times 100)$.

in fig 1 . No difference in the size of rectal crypts in alcohol abusers compared with controls was detected (table 1). However, the PI of the entire crypt column was significantly increased in patients compared with controls (table 1). This effect of alcohol consumption on PI values was maintained in the multiple regression analysis $(p=0.029)$. Neither sex $(p=0.47)$ nor cigarette smoking $(p=0.35)$ had a significant effect on PI. PI values of the various crypt compartments are shown in fig 2 . Figure 3 depicts the size of the PC which was enlarged in the heavy drinkers compared with controls (2.8 $v 2.35$ crypt compartments).

In addition, other markers of cellular regeneration, such as Ki67 and histone H3, were also found to be increased in patients compared with controls. Figure 4 shows examples of expression of Ki67 using immunohistology. Histone $\mathrm{H} 3$ using in situ hybridisation is shown in fig 5. Both histone $\mathrm{H} 3$ and Ki67 positive cells were markedly increased in study patients. In contrast, patterns of ck staining were identical in both groups: cells were uniformly positive for ck 8 and 19, and negative for ck 4 and 13. Also, no overall differences between alcoholics and controls were detected in the staining patterns of $\mathrm{Rb} 1$, bcl-2, and $\mathrm{p} 53$. Rb1 and bcl- 2 exhibited reactivity of few cells in the basal crypt region, and p53 was not detected.

\section{Discussion}

Our results show for the first time that heavy chronic alcohol consumption, regardless of the type of alcoholic beverage consumed, results in significantly increased rectal mucosal regeneration. This significant difference in cell regeneration was shown with three different proliferation markers. Quantitative analysis with PCNA staining also yielded information on the pattern of this alcohol associated rectal hyperproliferation. One important determinant to characterise the significance of crypt cell hyperproliferation is the extent of expansion of the PC of the crypt. Under normal conditions the lower third of the crypt represents the PC, followed by the functional compartment where cell division is greatly reduced and cells generally differentiate before they reach the colonic lumen. Expansion of the PC without crypt hyperplasia, as in this case, is typical for reparative cell growth following toxic damage
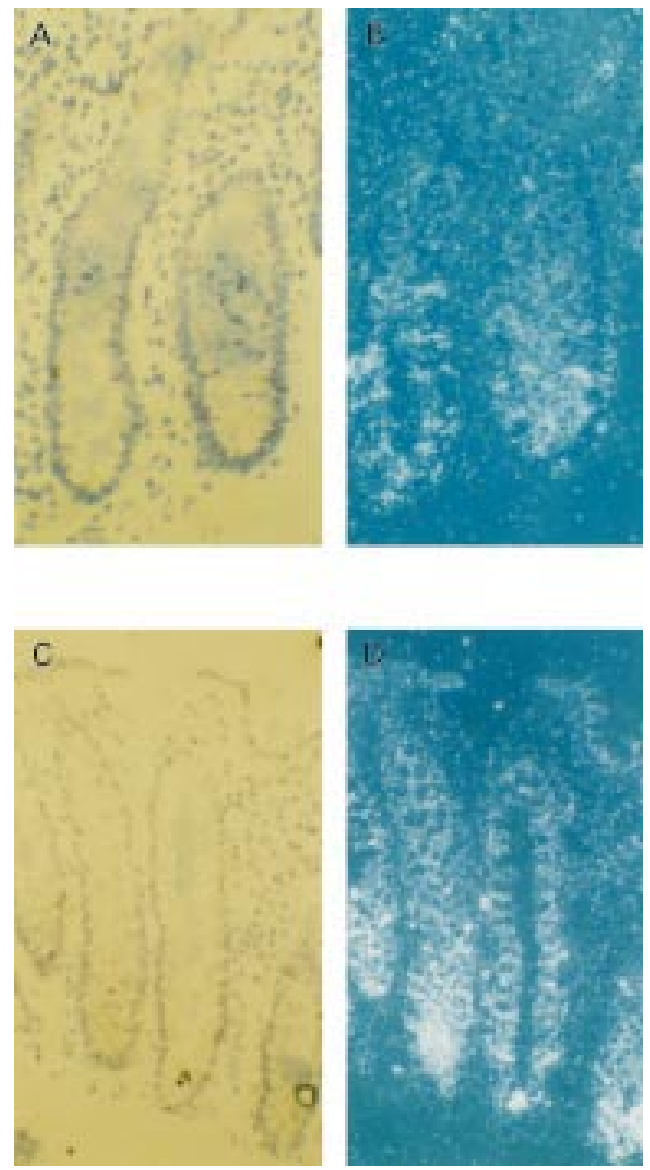

Figure 5 Histone H3 mRNA analysed by in situ hybridisation in rectal crypts of controls $(A, B)$ and alcoho abusers $(C, D) .(B)$ and $(D)$ are dark field

photomicrographs of $(A)$ and $(C)$, respectively. There was considerably increased $H 3 \mathrm{mRNA}$ in the proliferative regions of rectal crypts of alcoholic subjects (magnification $\times 80$ ).

of the mucosa and resembles the proliferative changes in the rectum of chronically alcohol fed experimental animals. ${ }^{12-14} \mathrm{~A}$ reduced survival time of crypt cells probably prevents hyperplasia as chronic ethanol consumption obviously leads to toxic cell damage and therefore to secondary compensatory hyperproliferation. ${ }^{13}$ Expansion of the PC is also associated with an increased risk of colorectal cancer and may represent a predictive marker for increased colorectal cancer risk, as shown in experimental animals ${ }^{16}$ as well as in humans. ${ }^{18} 19$

In addition to the quantitative PCNA study we investigated a second group of alcoholic patients and controls. In these subjects we stained rectal biopsy samples for Ki67 and histone H3. Ki67 is a nuclear non-histone protein which is expressed in cycling cells almost throughout the entire cell cycle, except early G-1. Therefore, it characterises approximately the growth fraction of the tissue under evaluation, ${ }^{23}$ although at a somewhat lower level. Reliable staining of $S$ phase cells can be performed with in situ hybridisation for histone H3. ${ }^{24}$ Both proliferation markers Ki67 and histone $\mathrm{H} 3$ showed markedly increased staining in rectal crypts of patients compared with controls. This was associated with expansion of the 
proliferative zone towards the colonic lumen. The percentage of $\mathrm{H} 3$ positive cells was found to be naturally lower compared with Ki67. Hence we confirmed increased rectal mucosal cell proliferation with three different methods in heavy drinking subjects. As snap frozen tissue samples yielded the same results for Ki67 and histone $\mathrm{H} 3$ as the PCNA study with formalin fixed tissues, fixation artefacts can be ruled out.

In experimental studies a significant correlation between crypt cell production rates and mucosal acetaldehyde concentrations was reported in the rectal mucosa of chronically ethanol consuming animals. ${ }^{12}{ }^{14}$ The acetaldehyde found in the colorectal mucosa and also in the lumen of the large intestine is predominantly produced by faecal bacteria. ${ }^{12} 2526$ These bacteria are capable of metabolising ethanol (which exists in the colonic lumen in similar concentrations as in blood) to acetaldehyde. Because of the large number of bacteria present, it is not surprising that acetaldehyde concentrations in the large intestine are the highest found in the body when calculated per gram of tissue ${ }^{27}$ and it is well established that acetaldehyde binds rapidly to $\operatorname{protein}^{28}$ and even to $\mathrm{DNA}^{29}$ resulting in cell injury. ${ }^{30}$ Indeed, the functional compartment of rectal crypts is smaller and the lifespan of the cells in the functional compartment is reduced, indicating destruction of mucosal cells when alcohol is fed to rats chronically. ${ }^{13}$ Furthermore, rectal biopsies of alcoholics revealed altered histology with inflammatory infiltrates. ${ }^{31}$ This histological feature returns to normal following three weeks of abstinence. ${ }^{31}$ Also, hyperplastic and hyperproliferative changes could be induced in the upper gastrointestinal tract of experimental animals after oral administration of acetaldehyde. ${ }^{15}$ Besides the fact that acetaldehyde can be produced by faecal bacteria, mucosal alcohol dehydrogenase is also capable of generating acetaldehyde. ${ }^{32}$ If acetaldehyde is not adequately metabolised further to acetate by acetaldehyde dehydrogenase (ALDH), it may accumulate and its toxic effects may aggravate. Indeed, a recent study by Yokoyama et al reported an increased risk of rectal cancer in individuals who possess a mutant ALDH-2 not capable of removing acetaldehyde adequately, which is another important finding focusing on the carcinogenic or tumour promoting effect of acetaldehyde in humans. ${ }^{33}$

Another possible mechanism of increased cell proliferation in heavy drinkers could be alcohol withdrawal itself, as rectal biopsies were taken during hospitalisation and abstinence. High amounts of alcohol may inhibit cell proliferation, at least in the liver, ${ }^{34}$ while moderate alcohol consumption results in hepatic hyperproliferation. ${ }^{35}$

We could not find any effect of chronic alcohol consumption on expression of $\mathrm{p} 53$, which is not surprising as overexpression of p53 is a late event in carcinogenesis often observed in neoplastic polyps. In addition, alcohol did not affect expression of $\mathrm{Rb} 1$. There was weak activity in a few basal cells but no difference between the two groups. However, it must be emphasised that the function of Rb1 depends on its phosphorylation and this cannot be elucidated by the method used.

The bcl-2 protooncogene is involved in the regulation of programmed cell death where it opposes induction of apoptosis. ${ }^{36}$ In normal colorectal crypts only a few cells at the base of the crypts are bcl-2 positive, which may represent putative stem cells. ${ }^{37}$ As alcohol ingestion leads to mucosal hyperregeneration and expansion of the PC of rectal crypts without changes in protooncogene expression, chronic ethanol consumption seems to affect early events in rectal tumorigenesis. The occurrence of mucosal hyperregeneration is indeed such an early event, according to Fearon and Vogelstein. ${ }^{38}$ However, folic acid deficiency could be an additional factor in a situation where mucosal hyperproliferation occurs. ${ }^{39}$ Indeed there seems to be a link between high alcohol intake, folate deficiency, and increased colorectal cancer risk. ${ }^{41}{ }^{42}$ Most recently, low folate levels were demonstrated in the rectal mucosa of rats after chronic alcohol ingestion. ${ }^{43}$ Due to the increased folate requirement for cytosine methylation and thymidine synthesis under hyperproliferative conditions, such folate deficiency may be an additional relevant factor in alcohol associated rectal carcinogenesis. Indeed, DNA hypomethylation has recently been reported in the rat colon following chronic alcohol consumption. ${ }^{44}$ Furthermore, acetaldehyde may itself be responsible for local folate deficiency as acetaldehyde, in concentrations present in the colon, destroys folate. ${ }^{45}$

To evaluate epithelial differentiation, we immunostained for different cytokeratins. The colorectal crypt cells of patients as well as controls exhibited the usual cytokeratin expression pattern with positive staining for cytokeratins 8 and 19, and no immunoreactivity for cytokeratins 4 and 13, the latter being normally expressed in squamous epithelia. ${ }^{46}$

In conclusion, we demonstrated here for the first time increased mucosal cell proliferation with expansion of the PC in rectal crypts of patients with chronic alcohol abuse. This is a condition associated with an increased risk of rectal cancer.

We thank Mrs Antje Schuhmann for expert technical assistance.

1 Stemmermann GN. Geographic epidemiology of colorectal cancer: The role of dietary fat. In: Seitz HK, Simanowski UA, Wright NA, eds. Colorectal cancer-from pathogenesis to UA, Wright NA, eds. Colorectal cancer-from pathogen
prevention. Heidelberg: Springer Verlag, 1989:3-23.

prevention. Heidelberg: Springer Verlag, 1989:3-23.
2 Weisburger JH, Horn CL. The causes of cancer. In: Holleb AI, Fink DJ, Murphy GP, eds. American Cancer Societary AI, Fink DJ, Murphy GP, eds. American Cancer Societary text book of clinical oncology.
Society Inc., 1991:80-98.

3 Scheppach W, Bingham S, Boutron-Ruault MC, et al. WHO consensus statement on the role of nutrition in colorectal cancer. Eur f Cancer Prev 1999;8:57-62.

4 Pollack ES, Nomura AMY, Heilbrun LK, et al. Prospective study of alcohol consumption and cancer. $N$ Engl $\mathcal{F} M e d$ 1984;310:617-21

5 Wu AH, Paganini-Hill A, Ross RK, et al. Alcohol, physical activity and other risk factors for colorectal cancer: a prospective study. Br 7 Cancer 1987;55:687-94.

6 Kune GA, Vitetta L. Alcohol consumption and the etiology of colorectal cancer: a review of the scientific evidence from 1957 to 1991. Nutr Cancer 1992;18:97-111.

7 Kikendall JW, Bowen PE, Burgess MB, et al. Cigarettes and alcohol as independent risk factors for colonic adenomas. Gastroenterology 1989;97:660-4.

8 Martinez ME, MacPherson RS, Annegers JF, et al. Cigarette smoking and alcohol consumption as risk factors for colorectal adenomatous polyps. F Natl Cancer Inst 1995;87:2749. 
9 Kearney J, Giavanucci E, Rimm EB. Diet, alcohol and smoking, and the occurence of hyperplastic polyps of the

Seitz HK, Czygan P, Waldherr R, et al. Enhancement of 1,2 dimethylhydrazine-induced rectal carcinogenesis following chronic ethanol consumption in the rat. Gastroenterology 1984;86:886-91

11 Hamilton SR, Hyland J, McAvinchey D, et al. Effects of chronic dietary beer and ethanol consumption on experimental colonic carcinogenesis by azoxymethane in rats. Cancer Res 1987;47:1551-9.

12 Seitz HK, Simanowski UA, Garzon FT, et al. Possible role of acetaldehyde in ethanol-related rectal cocarcinogenesis in the rat. Gastroenterology 1990;98:406-13.

13 Simanowski UA, Seitz HK, Baier B, et al. Chronic ethanol consumption selectively stimulates rectal cell proliferation in the rat. Gut 1986;27:278-82.

14 Simanowski UA, Suter P, Russell RM, et al. Enhancement of ethanol induced rectal mucosal hyper-regeneration with age in F344 rats. Gut 1994;35:1102-6.

15 Homann N, Kärkkäinen P, Koivisto T, et al. Effects of acetaldehyde on cell regeneration and differentiation of the upper gastrointestinal tract mucosa. F Natl Cancer Inst 97;89:1692-7.

16 Deschner EE, Long FC, Hakissian M, et al. Differential susceptibility of inbred mouse strains forecast by acute colonic proliferative response to methylazoxymethanol. $\mathcal{F}$ Natl Can cer Inst 1984;72:195-8.

17 Williamson RCN, Bauer FLR, Oscarson JEA, et al. Promotion of azoxymethane-induced colonic neoplasia by resection of the small bowel. Cancer Res 1978;38:3112-17.

18 Deschner EE, Lipkin M. Proliferative pattern in colonic mucosa in familial polyposis. Cancer 1975;35:413-18.

19 Eastwood GL, Trier JS. Epithelial cell renewal in cultured rectal biopsies in ulcerative colitis. Gastroenterology 1973; 64:383-90

20 Weisgerber UM, Boenig H, Nemitz R, et al. Proliferation cell nuclear antigen (clone 19A2) correlates with 5-bromo2-deoxyuridine labelling in human colonic epithelium. Gut 1993;34:1587-92.

21 Wright NA, Watson A, Morley A, et al. Cell kinetics in flat (avillous) mucosa of the human small intestine. Gut 1973, 14:701-10.

22 Bosch FX, Udvarhelyi N, Venter E, et al. Expression of the histone $\mathrm{H} 3$ gene in benign, semi-malignant and malignan lesions of the head and neck: a reliable proliferation marker. Eur F Cancer 1993;29A:1454-61.

23 Haldane JS, Scott RJ, Wright NA. Does the use of Ki67 allow the determination of tumour growth fraction? Pathol 1990;160:155.

24 Bosch FX, Udvarhelyi N, Venter E, et al. Expression of histone $\mathrm{H} 3$ gene in benign, semi-malignant and malignant a reliable proliferaion marker. Eur f Cancer 1993;29A:1454-61.

25 Jokelainen K, Matysiak-Budnik T, Mäkisalo H, et al. High intracolonic acetaldehyde values produced by a bacteriocolonic pathway for ethanol oxidation in piglets. Gut 1996;39: $100-4$.

26 Jokelainen K, Nosova T, Koivisto T, et al. Inhibition of bacteriocolonic pathway for ethanol oxidation by ciprofloxacin teriocolonic pathway for ethanol oxi
27 Seitz HK, Simanowski UA, Peters TJ. Alcohol and cancer. Hepatology 1987;7:616.

28 Tuma DJ, Sorrell MF. The role of acetaldehyde adducts in liver injury. In: Hall P, ed. Alcoholic liver disease: pathology and pathogenesis. London: Edwared Arnold Publ., 1995:8999

29 Vaca CE, Fang JL, Schweda EKH. Studies of the reaction of acetaldehyde with deoxynucleosides. Chem Biol Interact 1995;98:51-67.

30 Seitz HK, Pöschl G, Simanowski UA. Alcohol and cancer In: Galanther M, ed. Recent developments in alcoholism, vol. 14. The consequences of alcoholism. New York: Plenum Press, 1998:67-95.

31 Brozinski S, Fami K, Grosberg JJ. Alcohol ingestion induced changes in the human rectal mucosa: Light and electromi-
croscopic studies. Dis Colon Rectum 1979;21:329-35.

32 Seitz HK, Egerer G, Oneta C, et al. Alcohol dehydrogenase in the human colon and rectum. Digestion 1996;57:105-8.

33 Yokoyama A, Muramatsu T, Ohmori T, et al. Alcohol related cancers and aldehyde dehydrogenase- 2 in Japanese alcoholics. Carcinogenesis 1998;19:1383-7.

34 Diehl AM, Chacon M, Wagner P. The effect of chronic thanol feeding on ornithine decarboxylase activity and liver regeneration. Hepatology 1988;8:237-42.

35 Zhang M, Gong Y, Corbin I, et al. Light ethanol consumption enhances liver regeneration after partial hepatectomy in rats. Gastroenterology 2000;119:1333-9.

36 Reed JC. Bcl-2 and the regulation of programmed cell death. F Cell Biol 1993;124:1-6.

37 Merritt AJ, Potten CS, Watson AJM, et al. Differential expression of bcl-2 in intestinal epithelia. If Cell Sci 1995; 108:2261-71.

38 Fearon ER, Vogelstein B. A genetic model for colorectal tumorigenesis. Cell 1990;61:759-67.

39 Rosenberg IH. Folate, dysplasia, and cancer. Gastroenterology 1989;97:502-3.

40 Lashner BA, Heidenreich PA, Su GL, et al. Effect of folate supplementation on the incidence of dysplasia and cancer in chronic ulcerative colitis. Gastroenterology 1989:97:2559.

41 Giovannucci E, Rimm EB, Ascherio A, et al. Alcohol, low-methionine-low-folate diets, and risk of colon cancer in men. F Natl Cancer Inst 1995;87:265-73.

42 Boutron-Ruault M-C, Senesse P, Faivre J, et al. Folate and alcohol intakes: Related or independent roles in the adenoma-carcinoma sequence? Nutr Cancer 1996;26:33746.

43 Homann N, Tillonen J, Salaspuro M. Microbially produced acetaldehyde from ethanol may increase the risk of colon cancer via folate deficiency. Int F Cancer 2000;86:169-73.

44 Choi SW, Stickel F, Baik HW, et al. Chronic alcohol consumption induces genomic, but not p53-specific, DNA hypomethylation in the colon of the rat. F Nutr 1999;129: 1945-50

45 Shaw S, Jayatilleke E, Herbert V, et al. Cleavage of folates during ethanol metabolism: Role of acetaldehyde/xanthine during

46 Moll R, Franke WW, Schiller DL, et al. The catalog of human cytokeratins: Patterns of expression in normal epithelia, tumors and cultured cells. Cell 1982;31:11-24. 